\title{
Isolation, Cultivation and Identification of Spermatogonial Stem Cells from Juvenile Buffalo Testes
}

Huan Yang ${ }^{1}$, Tingting Li ${ }^{1}$, Huimin $\mathrm{Zhao}^{1,2}$, Xiaoyuan Zhang ${ }^{1}$, Huiyan Xu' ${ }^{1}$, Yangqing Lu ${ }^{1}$, Xingwei Liang ${ }^{1}$, Shengsheng Lu', Xiaogan Yang ${ }^{1 *}$ and Kehuan Lu ${ }^{1 *}$

${ }^{1}$ State Key Laboratory for Conservation and Utilization of Subtropical Agrobioresources, Guangxi High Education Key Laboratory for Animal Reproduction and Biotechnology, College of Animal Science and Technology.

${ }^{2}$ College of Life Science and Technology, Guangxi University, Nanning 530005, China

\begin{abstract}
A B S T R A C T
Spermatogonial stem cells (SSCs), a class of primitive germ cells located on the basement of the seminiferous tubules of the testes, are the only kind of adult stem cells that can pass their genetic material to offspring and are also capable of proliferation and differentiation, ensuring the efficiency of passing transgenes from parents to subsequent generations. In this research, to understand the growth characteristics of buffalo SSCs in vitro, methods for their isolation, enrichment, culture and preliminary identification were established. Testes from 3- to 6-month-old buffalos were digested with two-step enzymatic treatment to obtain isolated single cells and then enriched with a differential plating method. Isolated SSCs were cultured on STO feeder cells with SSCs culture medium (SSCM), which is serum-free. SSCs began to proliferate on the second day and quickly formed grape-like clusters that were consistent with the morphological features of SSCs. These cells were identified as positive by immunofluorescence staining. This study successfully isolated, enriched and identified buffalo SSCs and established an effective platform to explore the mechanisms of proliferation and differentiation of buffalo SSCs.
\end{abstract}

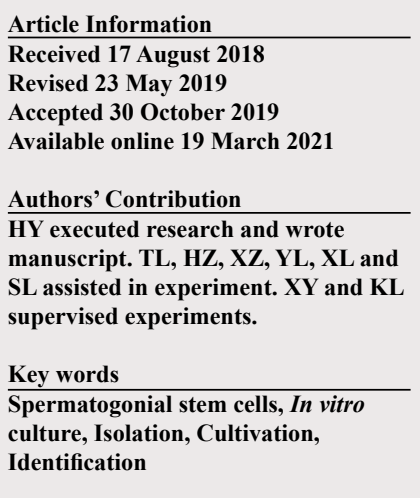

Article Information Received 17 August 2018 Accepted 30 October 201 Available online 19 March 202

Authors' Contribution HY executed research and wrot mincript. TL, HZ, XZ, YL, XL and supervised experiments.

Spermatogonial stem cells, In vitro Identification

\section{INTRODUCTION}

$\mathrm{B}$ uffalo are mainly distributed in sub-tropical areas and serve as very important animals for the economy in south China. To meet the requirements for animal husbandry products, China introduced buffalo from abroad to improve the germplasm resources of local buffalo. These measures have significantly increased the milk production of crossed offspring, but the reproductive rate of the buffalo has yet to be improved.

Spermatogonial stem cells (SSCs) are germ cells located at the basal part of the seminiferous tubules in male mammals (Huckins, 1971; de Rooij, 1973; Lok et al., 1982). They are the only somatic stem cells in animals that can transmit genetic material to the next generation (Dadoune, 2007). SSCs are the initial cells in the process of spermatogenesis, and they play an important role in male reproduction and have a very efficient ability to produce sperm (Oatley et al., 2011). SSCs have become an important subject of research in modern breeding processes and

\footnotetext{
Corresponding author: xgyang@gxu.edu.cn; khlu@ gxu.edu.cn 0030-9923/2021/0003-0859 \$ 9.00/0

Copyright 2021 Zoological Society of Pakistan
}

have shown the potential to improve animal reproductive rates. SSCs play an important role in reproductive biology research, transgenic animal technology research, reverse differentiation induced pluripotent stem cell research, animal germplasm conservation research and clinical research of tissue and organ rehabilitation.

SSCs are self-renewable to maintain their constant number and are capable of differentiating into spermatocytes (Wall et al., 1992; Wall, 2002; Brophy et al., 2003; Oatley and Brinster, 2008). The self-renewing ability of SSCs is the basis for males to produce sperm continuously. Morphological observation of SSCs by transmission electron microscopy is the most intuitive way to identify SSCs. To date, no specific molecular markers are available for the identification of buffalo SSCs. Buffalo SSCs are mainly identified by validating undifferentiated type A spermatogonial markers suitable for mice, cattle or goats in combination with germ cell-specific markers (Kossack et al., 2013; Zheng et al., 2014).

Thus far, not much is known about the SSCs of large animals, and the in vitro culture system of SSCs has not been established. Isolation, enrichment and in vitro culture are the basis of SSC research, which can provide materials for subsequent research.

In this research, the isolation, enrichment, culturing 
and identification of buffalo SSCs were expounded, which could supply a better research platform for the culture and identification of buffalo SSCs in vitro.

\section{MATERIALS AND METHODS}

\section{Collection of buffalo testes}

Three pairs of separated buffalo (Bubalus bubalis) testes from 3 to 6 months of age were collected from a Nanning slaughterhouse. Testes were kept in DMEM/ F12 (Gibco, 12440024) supplemented with penicillinstreptomycin (100U, ThermoFisher Scientific, 15140122) after disinfection with $75 \%$ alcohol and transported to the lab within $2 \mathrm{~h}$ on ice.

\section{Isolation and enrichment of SSCs from pubertal buffalo testes}

The isolation of SSCs from buffalo testes was performed using two-step enzymatic digestion treatment: testes were sterilized with $75 \%$ alcohol for 10 min twice and washed with phosphate buffered saline (PBS) for 3 times. The tunica albuginea was removed, and tissue was cut into little pieces. The tissue pieces were collected and then suspended with $2 \mathrm{mg} / \mathrm{mL}$ collagenase type IV (Sangon Biotech, LS004188). After incubated with the compound at $37^{\circ} \mathrm{C}$ for $40 \mathrm{~min}$ in a shaking water bath, tissue was washed with $10 \mathrm{~mL}$ of PBS 3 for times. Loose tissue was kept after centrifugation at $2000 \mathrm{rpm}$, then incubated with $5 \mu \mathrm{g} / \mathrm{mL}$ DNAase I (Worthingtom Biochemical Corp, LS002138) and $1.5 \mathrm{mg} / \mathrm{mL}$ hyaluronidase II (Sigma, $\mathrm{H} 2126$ ) diluted with DMEM/F12 for $20 \mathrm{~min}$ at $37^{\circ} \mathrm{C}$, washed with $10 \mathrm{~mL}$ of PBS for 3 times and centrifuged. The sediment was dissociated with $0.25 \%$ trypsin (Sangon Biotech, 3499B504) at $37^{\circ} \mathrm{C}$ for $10 \mathrm{~min}$ in a shaking water bath, and DMEM/F12 containing $10 \%$ foetal bovine serum (FBS, Hyclone, 30070.03) was added to halt digestion. The sediment was harvested after centrifugation and filtered with $70-\mu \mathrm{m}$ and $40-\mu \mathrm{m}$ cell strainers (BD) successively. Cells were incubated with DMEM/F12 containing 10\% FBS at $32.5^{\circ} \mathrm{C}$ for $60 \mathrm{~h}$ on $0.1 \%$ gelatin (Sigma, $119 \mathrm{~K} 0062$ ) coated dishes.

Then, SSCs were enriched with the differential planting method with laminin and collagen. Laminin is an extracellular matrix component and a specific surface marker of SSCs (Guan et al., 2009), so it was used to enrich SSCs (Shinohara et al., 1999). Collagen has no SSC binding activity (Hamra et al., 2005). The adherent cells were mostly somatic cells and differentiated germ cells on gelatin, and the non-adherent cells were mostly SSCs. Non-adherent cells were collected, seeded in dishes coated with Collagen I from rat tail IV $(0.01 \%$, Sigma, C7661) and cultured at $32.5^{\circ} \mathrm{C}$ for $4 \mathrm{~h}$. The non-adherent cells were collected and seeded then in dishes coated with laminin $(18 \mu \mathrm{g} / \mu \mathrm{L}$, Sigma, L2020) for $40 \mathrm{~min}$. The adherent cells were collected with $0.5 \%$ BSA-PBS (Sigma, A1470), and then the cells were cultured with SSC culture medium (SSCM) (Wu et al., 2013).

\section{Immunofluorescence of pubertal buffalo SSCS}

To identify stem characters of isolated and cultured SSCs, immunofluorescence experiments were performed. In this study, CDH1, PGP9.5 and c-Kit antibodies were selected for immunofluorescence staining of SSCs. $\mathrm{CDH} 1$ is an E-cadherin gene, which is involved in the anchoring of stem cells and the microenvironment during the oogenesis of Drosophila melanogaster, and Drosophila that delete this gene will stop oogenesis. CDH1 has been proven to be a marker of undifferentiated SSCs in mice and pigs (Tokuda et al., 2007; Zhao et al., 2016). PGP9.5, also known as UCHL1 or protein gene product 9.5 , belongs to the ubiquitin $\mathrm{C}$ terminal hydrolase family; its protein is specifically expressed in neurons and cells of the neuroendocrine systems and is expressed in undifferentiated SSCs in all age groups, except in human beings, such as buffalo, cattle and pigs (Tegelenbosch and de Rooij, 1993; Tokuda et al., 2007; Goel et al., 2010; He et al., 2010; Fujihara et al., 2011), promoting the proliferation of SSCs. c-Kit is an important member of the tyrosine kinase receptor protein family, and as a receptor of stem cell factor (SCF), it participates in the regulation of a series of signalling pathways and is related to the proliferation of stem cells (Tsai et al., 1991). The dilution rate of CDH1 (Santa Cruz, SC-31021), PGP9.5 (Abd Serotec, 7863-1004) and c-Kit (Santa Cruz, SC-168) were same at 1:200.

Cultured SSCs were fixed by $4 \%$ paraformaldehyde at room temperature and blocked with normal goat serum for 30 min separately. The cells were incubated with primary antibodies at $4{ }^{\circ} \mathrm{C}$ overnight and a secondary antibody at room temperature for $1 \mathrm{~h}$. Hoechst 33342 at $10 \mu \mathrm{g} / \mathrm{mL}$ was applied for $3 \mathrm{~min}$ to stain nuclei. A negative control used $3 \%$ BSA to replace the primary antibody.

\section{Immunofluorescence of pubertal buffalo seminiferous tubules}

Immunofluorescence staining of paraffin testes sections was performed to identify SSCs in tissue. PGP9.5 was identified as a specific maker of spermatogonia of buffalo testes, and DDX4 was proven to be expressed in germ cells (Goel et al., 2010; Kim et al., 2015); 1:200 dilutions of PGP9.5 (Abd Serotec, 7863-1004) and DDX4 (Abcam, ab13840) were used in experiments. Testes of juvenile buffalo obtained from slaughterhouses were first used for paraffin sectioning. Then, the immunofluorescence 
steps were as follows: paraffin testes sections were dewaxed, rehydrated, and placed in $10 \mathrm{mM}$ sodium citrate for $10 \mathrm{~min}$ at $90^{\circ} \mathrm{C}$ for antigen retrieval, then treated with $0.5 \%$ Triton X-100 for $20 \mathrm{~min}$. Slices were blocked with $10 \%$ normal goat serum at room temperature for $30 \mathrm{~min}$, incubated with primary antibody at $4^{\circ} \mathrm{C}$ overnight, and secondary antibody as applied at room temperature for 1 h. Finally, $10 \mathrm{mg} / \mathrm{mL}$ Hoechst 33342 was applied for 3 min for nuclear staining. After washing in PBS and fixation with gum, slides were viewed under a microscope. A negative control used 3\% BSA to replace the primary antibodies.

\section{Culturing of SSCs}

STO cells were treated with $0.015 \mathrm{mg} / \mathrm{mL}$ mitomycin $\mathrm{C}$ (produced by Haizheng) for $2 \mathrm{~h}$ as feeder layers of buffalo SSCs. The SSCs collected were then seeded on STO feeder cells, incubated with SSC culture medium (SSCM, patent number: CN201210549380.5, China), which uses DMEM/F12 (GIBCO, 12400024) as the basic medium supplemented with BSA for serum replacement (BSA, Sigma, A1470), GDNF (ProSpec, CYT-305), GFR $\alpha 1$ (R\&D systems, 560GR), bFGF (ProSpec, CYT-218), $\beta$-Me (Sangon Biotech, M0482-100 mL), Amphotericin B (Sangon Biotech, BS721) and penicillin-streptomycin (100 U, ThermoFisher Scientific, 15140122). The cells were cultured in a $5 \% \mathrm{CO}_{2}$ atmosphere at $37{ }^{\circ} \mathrm{C}$, and the culture medium was changed every other day.

\section{The propagation of SSCs in vitro}

The old SSCM was gently collected and discarded, PBS was added to wash away the floating-dead cells, and then PBS was added again and gently blown to collect surface cells that mostly consisted of poorly adherent SSCs. The collected cells were centrifuged, the supernatant was discarded, and the cells were resuspended with SSCM and seeded in a dish coated with a new STO feeder layer. The numbers of SSCs seeded and harvested from the first passage to the fourteenth were recorded, and their proliferation rate were calculated.

\section{RT-PCR to check the expression of SSC-specific transcription factors}

This experiment aimed to check whether SSCs cultured in vitro express SSC-specific genes, and the steps were as follows: prepare enough SSCs cultured in vitro, discard the medium and wash cultured SSCs twice with PBS. The total RNA was extracted by an RNeasy mini kit (QIAGEN, 74104), and then the OD260 and RNA concentration were measured with a spectrophotometer; all samples were adjusted to the same RNA concentration at $100 \mathrm{ng} / \mathrm{mL}$. cDNA was obtained by an RNA reverse transcription cDNA kit (TAKARA), and finally electrophoresis was performed on a $2 \%$ agarose gel to check the expression of SSC-specific transcription factors such as DDX4, DAZL, PLZF, and DAZL. Primers are given in Table III.

Ultrastructure of SSCs in testes and cultured in vitro observed under transmission electron microscopy

Buffalo SSCs cultured in vitro were harvested and centrifuged, and then cells were diluted 10 times by PBS, evenly dispersed, dripped onto copper mesh, and incubated at room temperature for 10 minutes; filter paper was used to absorb excess liquid, phosphotungstic acid was dripped onto the copper mesh with a dropper to cover it, and the whole copper mesh was incubated for $1 \mathrm{~min}$; finally, the copper wire was cleaned with pure water to dissolve and remove other impurities and excess phosphotungstic acid. The mesh was dried naturally and observed with a Hitachi H-7650 transmission electron microscope.

Three to six-month-old buffalo testes was cut into small pieces of $1 \times 1 \times 2 \mathrm{~mm}^{3}$ for reserve; $2 \%$ glutaraldehyde was used to fix for $12 \mathrm{~h}$ and cleaned three times with PBS; the samples were treated with osmium acid for $12 \mathrm{~h}$ and cleaned three times with PBS again; 40\%, 70\%, 90\%, 100\% ethanol dehydration was performed, followed by the replacement of ethanol with acetone in the tissue; tissue was embedded and dried by epoxy resin Epon; an ultrathin slicing machine was used to cut the tissue into 90-nm slices; uranium acetate staining was performed for $5 \mathrm{~min}$, lead citrate staining for $5 \mathrm{~min}$, and PBS cleaning was performed 3 times; and at last, the slices were placed on copper wire and observed by transmission electron microscopy.

The ultrastructure of SSCs in testes and cultured in vitro were photographed and compared.

\section{RESULTS}

\section{Isolation and enrichment of the SSCs of pubertal buffalo testicular tissue}

In total, $0.30 \%$ to $0.53 \%$ SSCs were obtained from juvenile buffalo (Table I), and the ratio of SSCs to the total number of testicular cells decreased with increased buffalo aging; this result indicated that the number of the SSCs in juvenile male buffalo were much higher than those in mature buffalo and confirmed the fact that the number of the SSCs in testicular cells is very low. SSCs were separated and enriched by two-step enzymatic digestion treatment and the differential planting method, which indicated that this method was suitable for buffalo.

The purity of SSCs purified by the differential planting method is usually not high, and there are more somatic cells. However, compared with other separation methods, 
the differential planting method does not require the purchase of experimental equipment, is simple to operate, and the experimental cost is relatively low. After the twostep enzymatic digestion treatment, there were many cell types and different cell morphologies; testicular somatic cells, which were mainly Sertoli cells, adhered much faster, while germ cells were in a semi-adherent state (Fig. 1B). Germ cells floated because of weak adherence when pipetting, while testicular somatic cells (Fig. 1E) stayed in the culture dish. In the collagen-coated dish, somatic cells adhered to the wall, while germ cells did not (Fig. 1C), and germ cells were harvested gently by pipetting to enrich them $2 \mathrm{~h}$ later. After enrichment by collagen and laminin, enriched SSCs were co-cultured with an STO feeder layer previously treated with mitomycin C. Under serum-free culture medium, SSCs attached to STO cells, grew and began to proliferate (Fig. 1D). The SSCs could be used for subsequent studies.

Table I. Isolation rate of SSCs from juvenile buffalo testes.

\begin{tabular}{lllll}
\hline Age & $\begin{array}{l}\text { Wt of seminif- } \\
\text { erous tubule }\end{array}$ & $\begin{array}{l}\text { No. of testes } \\
\text { cells (Nt) }\end{array}$ & $\begin{array}{l}\text { No. of } \\
\text { SSCs (Ns) }\end{array}$ & Ns/Nt \\
\hline 3-month & $2.0 \mathrm{~g}$ & $2.85 \times 10^{6}$ & $1.5 \times 10^{4}$ & $0.53 \%$ \\
4.6-month & $3.5 \mathrm{~g}$ & $3.2 \times 10^{7}$ & $1.0 \times 10^{5}$ & $0.31 \%$ \\
5-month & $4.3 \mathrm{~g}$ & $6.93 \times 10^{7}$ & $2.5 \times 10^{5}$ & $0.30 \%$ \\
\hline
\end{tabular}

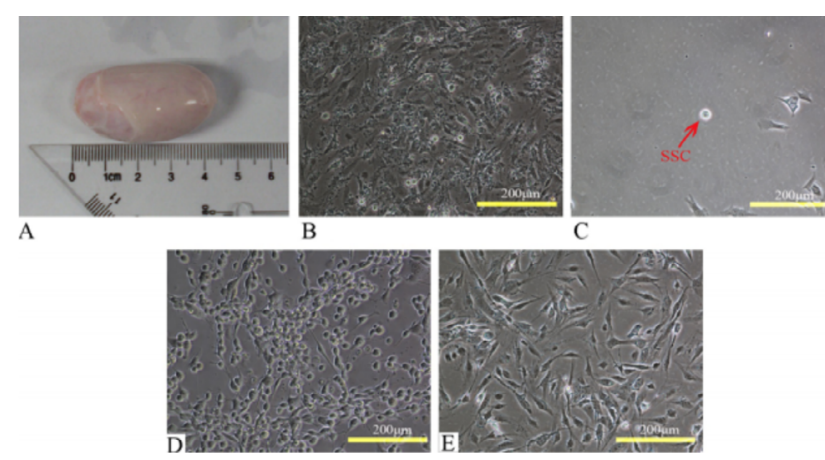

Fig. 1. Differential adherence enrichment of buffalo SSCs. A, Testes from a 3 month-old buffalo; B, in gelatintreated culture dishes, testicular somatic cells adhere to the surface of the dish before germ cells, and germ cells do not adhere firmly; $\mathrm{C}$, when purified in a culture dish coated with rat tail collagen, the adherent cells mainly consist of spermatogonia; D, co-culture of separated germ cells with STO; E, separated testicular somatic cells (mainly Sertoli cells).

In vitro culture of SSCS

A serum-free culture system let buffalo SSCs cells grow in a typical grape cluster (Fig. 2A), which supported the continuous culture of SSCs in vitro for more than 6 months and more than 32 passages. In the experiment, SSCs were frozen with serum-free cryopreservation solution purchased from Sigma. No morphological changes were observed in the frozen-thawed operation of buffalo SSCs, and the proliferation performance remained unchanged (Fig. 2B).
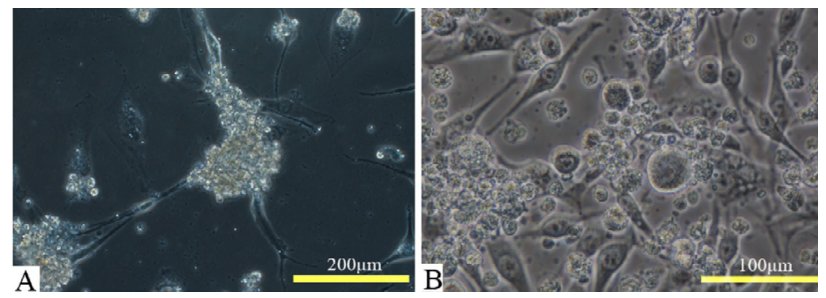

Fig. 2. In vitro culture of buffalo SSCs. SSCs attached to STO feeder layer for growth. A, The isolated and cultured buffalo SSCs were found in typical grape clusters; B, the frozen-thawed buffalo SSCs had no change in morphology and performance.

We performed a serial subculture of SSCs and found that the proliferation ability of buffalo SSCs in the serumfree culture system was not related to its passage numbers (Table II). Our result proved that the culture system used in the experiment is capable of maintaining the proliferation ability of buffalo SSCs in vitro.

Table II. Fold change of different passages of juvenile buffalo SSCs cultured in vitro.

\begin{tabular}{llll}
\hline Passage & Seeding (cells) & Harvest (cells) & Fold Change \\
\hline P1 & $11.0 \times 10^{4}$ & $49.5 \times 10^{4}$ & 4.50 \\
P2 & $3.35 \times 10^{4}$ & $20.0 \times 10^{4}$ & 5.33 \\
P3 & $5.00 \times 10^{4}$ & $24.0 \times 10^{4}$ & 4.80 \\
P4 & $45.42 \times 10^{4}$ & $90.8 \times 10^{4}$ & 2.00 \\
P5 & $24.00 \times 10^{4}$ & $78.0 \times 10^{4}$ & 3.25 \\
P6 & $26.00 \times 10^{4}$ & $70.4 \times 10^{4}$ & 2.71 \\
P7 & $11.7 \times 10^{4}$ & $48.0 \times 10^{4}$ & 4.10 \\
P8 & $29.0 \times 10^{4}$ & $72.0 \times 10^{4}$ & 2.48 \\
P9 & $12.5 \times 10^{4}$ & $55.6 \times 10^{4}$ & 4.45 \\
P10 & $45 \times 10^{4}$ & $80.0 \times 10^{4}$ & 1.78 \\
P11 & $5.0 \times 10^{4}$ & $23.0 \times 10^{4}$ & 4.60 \\
P12 & $3.00 \times 10^{4}$ & $18.0 \times 10^{4}$ & 6.00 \\
P13 & $12.0 \times 10^{4}$ & $54.0 \times 10^{4}$ & 4.50 \\
P14 & $13.5 \times 10^{4}$ & $60.0 \times 10^{4}$ & 4.40 \\
\hline
\end{tabular}

Characterization of biomarkers in pubertal buffalo testicular tissue and SSCS

Immunofluorescence staining results showed that 
SSCs of juvenile buffalo cultured in vitro expressed c-Kit, CDH1 and PGP9.5 (Fig. 4); DDX4 and PGP9.5 were expressed in tissue containing SSCs (Fig. 5) and both tissue and in vitro SSCs expressed PGP9.5. PGP9.5 has been proven to be a specific marker for the identification of SSCs of buffalo (Goel et al., 2010). c-Kit has been proven to be associated with stem cell proliferation (Tsai et al., 1991). The immunofluorescence staining results showed that c-Kit, CDH1, PGP9.5 and DDX4 were expressed in buffalo SSCs, and they could be used as markers to identify buffalo SSCs. SSCs cultured in vitro maintained the characteristics of SSCs in vivo, and this result shows that the SSCs we cultured could be used for subsequent experiments.

Table III. Expected product length and sequence of primers used in RT-PCR.

\begin{tabular}{lll}
\hline Gene & $\begin{array}{l}\text { Product } \\
\text { length } \\
\text { (bp) }\end{array}$ & \\
\hline GAPDH & 221 & F; 5'-CGTGGAGGGACTTATGACCAC-3' \\
& & R:5'-CCACAACAGACACGTTGGGA-3' \\
DDX4 & 123 & F: 5'-AACAGCGTCAGACCCTTATG-3' \\
& & R :5'-CTCTACATGCTCCACCCACT-3' \\
DAZL & 241 & F: 5'-AAGCCCTTCTGCTGCAAATC-3' \\
& & R : 5'-GACACACCAGTTCGATCCGT-3' \\
PLZF & 125 & F: 5'-GCAACAGCCAGCACTATACTCTG-3' \\
& & R: 5'-AGCGGCATACAGCAGGTCA-3' \\
OCT4 & 184 & F : 5'AAGCTGGACAAGGAGAAGCT-3' \\
& & R: 5'-TAGTCGTTTGGCTGAACACC-3' \\
\hline
\end{tabular}

Identification of gene expression of SSCs In vitro

In this experiment, the expression of SSC-specific genes was tested by RT-PCR. The PCR results showed that buffalo SSCs cultured in vitro expressed SSC-specific genes such as DDX4, DAZL, PLZF, and OCT4 (Fig. 3), but these factors were not expressed in the STO. The results showed that buffalo SSCs cultured in vitro maintained the characteristics of stem cells.
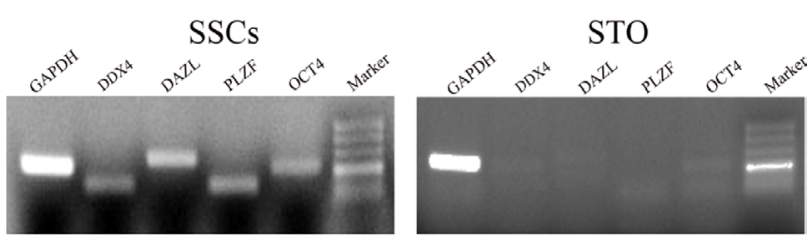

Fig. 3. Gene expression of buffalo SSCs and STO. DDX4 and DAZL are germline-related markers, PLZF is a buffalo spermatogonia marker and OCT4 is a pluripotency marker.

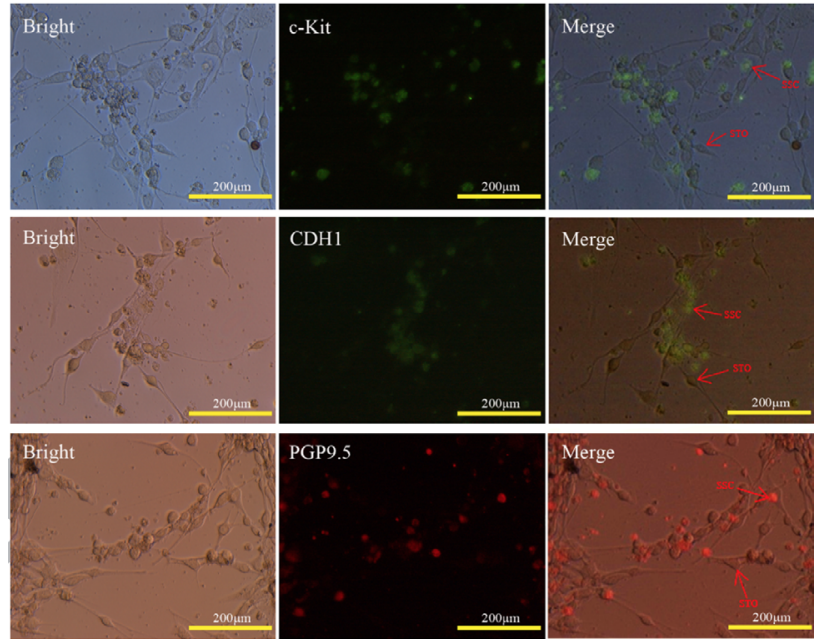

Fig. 4. Cellular immunochemical staining of buffalo SSCs. Grape-like cluster of SSCs expressing stem cell factors such as c-Kit, undifferentiated spermatogonia marker PGP9.5 and CDH1.
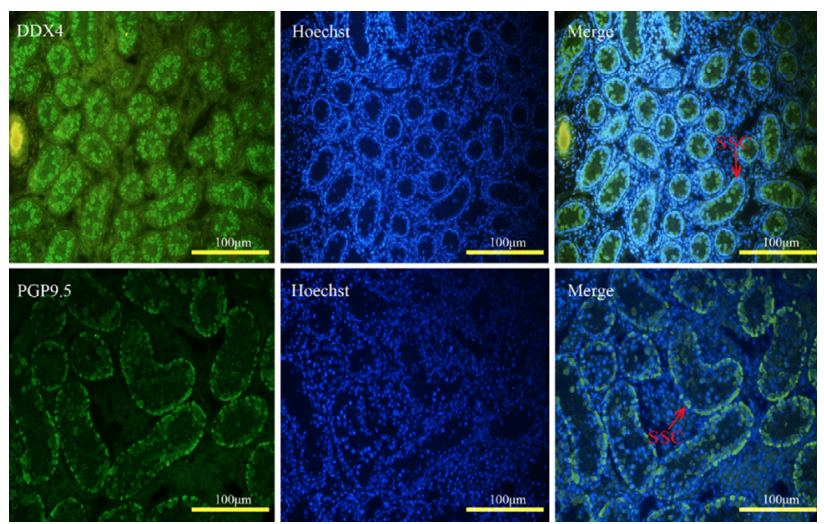

Fig. 5. Expression of the germline marker DDX4 and undifferentiated spermatogonia marker PGP9.5 in buffalo testes tissue.

Ultrastructure of SSCs in testes tissue and SSCs cultured In vitro

The transmission electron microscopy observation of buffalo SSCs showed that the SSCs in testicular samples were tightly adhered to the basement membrane (Fig. 6C), with low electron density, light staining and a diameter of approximately $20 \mu \mathrm{m}$. The intracellular genetic material was in a chromatin state with few or no nucleolus and few heterochromatins distributed evenly in the nucleus. Mitochondria were spherical and not abundant in cristae (Fig. 6D), the number of other organelles was not high, and the endoplasmic reticulum and Golgi apparatus were relatively rare. Sertoli cells were usually irregular (Fig. 6A, B), with higher electron density, deeper staining than SSCs, a lower nuclear-cytoplasmic ratio, more heterochromatin, 
distribution in the nucleoplasm, partly near the endonuclear membrane, and sometimes displaying dentate depression of the nuclear membrane (Fig. 6B); organelles were more abundant than SSCs, with more exosomes and Golgi apparatus. SSCs were surrounded by Sertoli cells, forming a microenvironment for the growth and differentiation of the SSC niche (Fig. 6C).

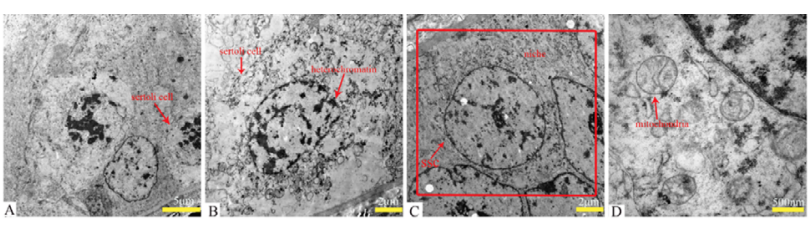

Fig. 6. Sertoli cells and niche in seminiferous tubules of buffalo testes under transmission electron microscopy. A-B, The shape of Sertoli cells is irregular, and heterochromatin is abundant; C, the SSCs are surrounded by Sertoli cells, which form a niche structure; D, the SSCs in testes have spherical mitochondria and few mitochondrial cristae.

In SSC samples cultured in vitro, due to the influence of culture conditions and sampling methods, SSCs were spherical with a diameter a little smaller than those of SSCs in testes, approximately $15 \mu \mathrm{m}$ (Fig. 7A, B). SSCs had no or few nucleoli, light chromatin staining, abundant euchromatin and very few heterochromatins. Mitochondria were abundant and nearly spherical with more mitochondrial cristae. (Fig. 7B). Apoptotic STO was observed under electron microscopy (Fig. 7C).
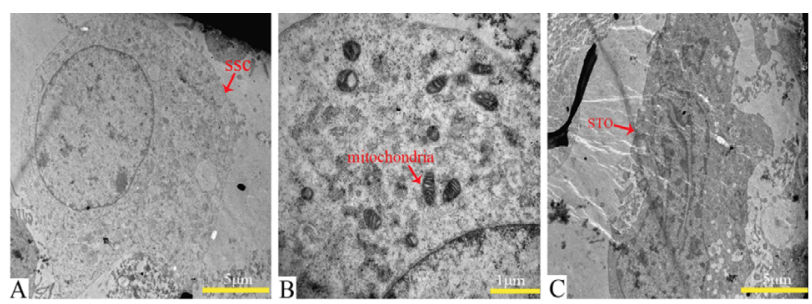

Fig. 7. In vitro cultured SSCs and STO under transmission electron microscopy. A, SSCs have a high nucleuscytoplasm ratio, are $15 \mu \mathrm{m}$ in diameter, and have less heterochromatin; B, SSCs cultured in vitro have more mitochondrial cristae; $\mathrm{C}$, apoptotic STO cell.

From electron microscopic observation of testes and in vitro culture-sourced SSCs, we confirm that there were no significant differences in size, nuclear-cytoplasmic ratio, genetic material morphology, mitochondrial morphology, organelle type and numbers. We can conclude that SSCs cultured in vitro have the same morphological characteristics as SSCs in testes. The serum-free culture system used in the culturing experiment supports the proliferation and characteristics of buffalo SSCs.

\section{DISCUSSION}

SSCs are the only stem cells in adult mammalian males that can transfer genetic material to the next generation. The number of SSCs in testes is very small, and there are various types of spermatogonia and other types of somatic cells in testes. Based on these two reasons, SSCs are difficult to separate (Shinohara et al., 1999; Meachem et al., 2001). Researchers have used the two-step enzymatic digestion method to successfully isolate the SSCs from mouse, rat and pig (Dirami et al., 1999), and in this study, buffalo SSCs were also separated by this method. The cells isolated and cultured in our lab expressed DDX4, DAZL, PLZF, and OCT4, which are SSC-specific transcription factors, which implies that buffalo SSCs were kept stem cell characters. It was found that the proportion of SSCs in the testes of younger buffalo age at 6 months was much higher than in mature buffalo (Tegelenbosch and de Rooij, 1993). This result was the same as that in mice (Shinohara et al., 2001), which also confirms that the ratio of SSCs in testicular cells is very low.

At present, the in vitro culture methods of SSCs are mostly based on the improvement of three SSCs culture methods in mice (Kanatsu-Shinohara et al., 2003; Kubota et al., 2004; Hamra et al., 2005). The long-term culture of SSCs in mice and rats has been successful, while the development of large animals is relatively slow, and only the short-term culture of SSCs has been reported (Bahadorani et al., 2012; Heidari et al., 2012; Kala et al., 2012), but our experiment successfully established a buffalo SSC cell line in vitro. One of the typical characteristics of SSCs is their self-renewal ability (Sato et al., 2011), we also found in our data of proliferation ability of SSCs that the increase number of stem cells is not a behavior of these cell as it can be decided by human being, whereas cell proliferation rate reflected the intrinsic property of these cell.

In our immunofluorescence staining experiments, the result indicated that PGP9.5 could be used as a specific marker of buffalo SSCs, which was consistent with previous research results (Goel et al., 2010). However, due to the scarcity of useful buffalo antibodies, the exploration of immunofluorescence identification was limited.

There was no obvious difference in the ultrastructure of SSCs in testes and cultured in vitro. We observed that SSCs have few organelles including mitochondria, which was consistent with previous studies (Lacerda et al., 2014). However, SSCs cultured in vitro had more mitochondria and mitochondrial cristae than in testes, indicating that the energy metabolism of SSCs in vitro was more active, which might be related to the enhanced proliferation of SSCs in culture system. 


\section{CONCLUSION}

In this study, we established a culture and identification system for buffalo SSCs, provided a reference for the research and utilization of other mammals and even human SSCs, provided a new method for germplasm conservation, and a theoretical basis for the clinical research and application of SSCs.

\section{ACKNOWLEDGEMENTS}

This research project is supported by the fund of Innovation Project of Guangxi Graduate Education (project number YCBZ2013008), Study Abroad Program for Excellent Ph.D. Students of Guangxi Zhuang Autonomous Region, the Natural Science Foundation of China (No. 31872350, No.31460601) and the Natural Science Foundation of Guangxi (2018GXNSFAA281004). Thank Prof. Yingji Wu and Ms. Fenhua Luo for their helps of cell culture and maintenance of stem cells for the present work.

Conflict of interest statement

Authors have declared no conflict of interest.

\section{REFERENCES}

Bahadorani, M., Hosseini, S.M., Abedi, P., Hajian, M., Hosseini, S.E., Vahdati, A., Baharvand, H. and Nasr-Esfahani, M.H., 2012. Short-term in-vitro culture of goat enriched spermatogonial stem cells using different serum concentrations. J. Assist. Reprod. Genet., 1: 39-46. https://doi.org/10.1007/ s10815-011-9687-5

Brophy, B., Smolenski, G., Wheeler, T., Wells, D., L'Huillier, P. and Laible, G., 2003. Cloned transgenic cattle produce milk with higher levels of beta-casein and kappa-casein. Nat. Biotechnol., 2: 157-162. https://doi.org/10.1038/nbt783

Dadoune, J.P., 2007. New insights into male gametogenesis: What about the spermatogonial stem cell niche? Folia Histochem. Cytobiol., 3: 141-147.

de Rooij, D.G., 1973. Spermatogonial stem cell renewal in the mouse. I. Normal situation. Cell Tissue Kinet., 3: 281-287. https://doi. org/10.1111/j.1365-2184.1973.tb01617.x

Dirami, G., Ravindranath, N., Pursel, V. and Dym, M., 1999. Effects of stem cell factor and granulocyte macrophage-colony stimulating factor on survival of porcine type a spermatogonia cultured in ksom. Biol. Reprod., 1: 225-230. https://doi.org/10.1095/ biolreprod61.1.225
Fujihara, M., Kim, S.M., Minami, N., Yamada, M. and Imai, H., 2011. Characterization and in vitro culture of male germ cells from developing bovine testis. $J$. Reprod. Dev., 3: 355-364. https://doi.org/10.1262/ jrd.10-185M

Goel, S., Reddy, N., Mandal, S., Fujihara, M., Kim, S.M. and Imai, H., 2010. Spermatogonia-specific proteins expressed in prepubertal buffalo (bubalus bubalis) testis and their utilization for isolation and in vitro cultivation of spermatogonia. Theriogenology, 7: 1221-1232. https://doi. org/10.1016/j.theriogenology.2010.05.025

Guan, K., Wolf, F., Becker, A., Engel, W., Nayernia, K. and Hasenfuss, G., 2009. Isolation and cultivation of stem cells from adult mouse testes. Nat. Protoc., 2: 143-154. https://doi.org/10.1038/nprot.2008.242

Hamra, F.K., Chapman, K.M., Nguyen, D.M., WilliamsStephens, A.A., Hammer, R.E. and Garbers, D.L., 2005. Self renewal, expansion, and transfection of rat spermatogonial stem cells in culture. Proc. natl. Acad. Sci. U. S. A., 48: 17430-17435. https://doi. org/10.1073/pnas.0508780102

He, Z., Kokkinaki, M., Jiang, J., Dobrinski, I. and Dym, M., 2010. Isolation, characterization, and culture of human spermatogonia. Biol. Reprod., 2: 363-372. https://doi.org/10.1095/biolreprod.109.078550

Heidari, B., Rahmati-Ahmadabadi, M., Akhondi, M.M., Zarnani, A.H., Jeddi-Tehrani, M., Shirazi, A., Naderi, M.M. and Behzadi, B., 2012. Isolation, identification, and culture of goat spermatogonial stem cells using c-kit and pgp9.5 markers. $J$. Assist. Reprod. Genet., 10: 1029-1038. https://doi. org/10.1007/s10815-012-9828-5

Huckins, C., 1971. The spermatogonial stem cell population in adult rats. 3. Evidence for a longcycling population. Cell Tissue Kinet., 4: 335349. https://doi.org/10.1111/j.1365-2184.1971. tb01544.x

Kala, S., Kaushik, R., Singh, K.P., Kadam, P.H., Singh, M.K., Manik, R.S., Singla, S.K., Palta, P. and Chauhan, M.S., 2012. In vitro culture and morphological characterization of prepubertal buffalo (Bubalus bubalis) putative spermatogonial stem cell. J. Assist. Reprod. Genet., 12: 1335-1342. https://doi.org/10.1007/s10815-012-9883-y

Kanatsu-Shinohara, M., Ogonuki, N., Inoue, K., Miki, H., Ogura, A., Toyokuni, S. and Shinohara, T., 2003. Long-term proliferation in culture and germline transmission of mouse male germline stem cells. Biol. Reprod., 2: 612-616. https://doi.org/10.1095/ biolreprod.103.017012

Kim, J.Y., Jung, H.J. and Yoon, M.J., 2015. Vasa 
(ddx4) is a putative marker for spermatogonia, spermatocytes and round spermatids in stallions. Reprod. Domest. Anim., 6: 1032-1038. https://doi. org/10.1111/rda.12632

Kossack, N., Terwort, N., Wistuba, J., Ehmcke, J., Schlatt, S., Scholer, H., Kliesch, S. and Gromoll, J., 2013. A combined approach facilitates the reliable detection of human spermatogonia in vitro. Hum. Reprod., 11: 3012-3025. https://doi.org/10.1093/humrep/det336

Kubota, H., Avarbock, M.R. and Brinster, R.L., 2004. Growth factors essential for self-renewal and expansion of mouse spermatogonial stem cells. Proc. natl. Acad. Sci. U. S. A., 47: 16489-16494. https://doi.org/10.1073/pnas.0407063101

Lacerda, S.M., Costa, G.M. and de Franca, L.R., 2014. Biology and identity of fish spermatogonial stem cell. Gen. Comp. Endocrinol., pp. 56-65. https://doi. org/10.1016/j.ygcen.2014.06.018

Lok, D., Weenk, D. and De Rooij, D.G., 1982. Morphology, proliferation, and differentiation of undifferentiated spermatogonia in the chinese hamster and the ram. Anat. Rec., 1: 83-99. https:// doi.org/10.1002/ar.1092030109

Meachem, S., von Schonfeldt, V. and Schlatt, S., 2001. Spermatogonia: Stem cells with a great perspective. Reproduction, 6: 825-834. https://doi.org/10.1530/ rep. 0.1210825

Oatley, J.M. and Brinster, R.L., 2008. Regulation of spermatogonial stem cell self-renewal in mammals. Annu. Rev. Cell. Dev. Biol., pp. 263-286. https://doi. org/10.1146/annurev.cellbio.24.110707.175355

Oatley, M.J., Racicot, K.E. and Oatley, J.M., 2011. Sertoli cells dictate spermatogonial stem cell niches in the mouse testis. Biol. Reprod., 4: 639-645. https://doi. org/10.1095/biolreprod.110.087320

Sato, T., Katagiri, K., Yokonishi, T., Kubota, Y., Inoue, K., Ogonuki, N., Matoba, S., Ogura, A. and T. Ogawa, 2011. In vitro production of fertile sperm from murine spermatogonial stem cell lines. Nat Commun., 2: 472. https://doi.org/10.1038/ ncomms 1478

Shinohara, T., Avarbock, M.R. and Brinster, R.L., 1999. Beta1- and alpha6-integrin are surface markers on mouse spermatogonial stem cells. Proc. natl. Acad. Sci. U. S. A., 10: 5504-5509. https://doi.org/10.1073/ pnas.96.10.5504
Shinohara, T., Orwig, K.E., Avarbock, M.R. and Brinster, R.L., 2001. Remodeling of the postnatal mouse testis is accompanied by dramatic changes in stem cell number and niche accessibility. Proc. natl. Acad. Sci. U. S. A., 11: 6186-6191. https://doi.org/10.1073/ pnas. 111158198

Tegelenbosch, R.A. and de Rooij, D.G., 1993. A quantitative study of spermatogonial multiplication and stem cell renewal in the $\mathrm{c} 3 \mathrm{~h} / 101 \mathrm{fl}$ hybrid mouse. Mutat. Res., 2: 193-200. https://doi. org/10.1016/0027-5107(93)90159-D

Tokuda, M., Kadokawa, Y., Kurahashi, H. and Marunouchi, T., 2007. Cdh1 is a specific marker for undifferentiated spermatogonia in mouse testes. Biol. Reprod., 1: 130-141. https://doi.org/10.1095/ biolreprod.106.053181

Tsai, M., Takeishi, T., Thompson, H., Langley, K.E., Zsebo, K.M., Metcalfe, D.D., Geissler, E.N. and Galli, S.J., 1991. Induction of mast cell proliferation, maturation, and heparin synthesis by the rat c-kit ligand, stem cell factor. Proc. natl. Acad. Sci. U. S. A., 14: 6382-6386. https://doi.org/10.1073/ pnas.88.14.6382

Wall, R.J., 2002. New gene transfer methods. Theriogenology, 1: 189-201. https://doi.org/10.1016/ S0093-691X(01)00666-5

Wall, R.J., Hawk, H.W. and Nel, N., 1992. Making transgenic livestock: Genetic engineering on a large scale. J. Cell Biochem., 2: 113-120. https://doi. org/10.1002/jcb.240490203

Wu, Y.J., L'uo, F.H., Zhang, Y., Sa, C.L., Su, H.M., L'iu, T.D., Yu, B.Y., L'iu, L.H., Bao, J.J., Kong, Q.F., Liu, D.Y. and Liu, Y., 2013. Spermatogonial stem cell culture medium of domestic animals. China Patent. CN 103074297 A.

Zhao, H.M., Yang, H., Luo, F.H., Li, M.X., Zhang, S., Yang, X.G., Lu, Y.Q., Lu, S.S., Wu, Y.J. and Lu, K.H., 2016. Isolation, proliferation, and induction of bama mini-pig spermatogonial stem cells in vitro. Genet. Mol. Res., 3: 15038602. https://doi. org/10.4238/gmr.15038602

Zheng, Y., Thomas, A., Schmidt, C.M. and Dann, C.T., 2014. Quantitative detection of human spermatogonia for optimization of spermatogonial stem cell culture. Hum. Reprod., 11: 2497-2511. https://doi.org/10.1093/humrep/deu232 